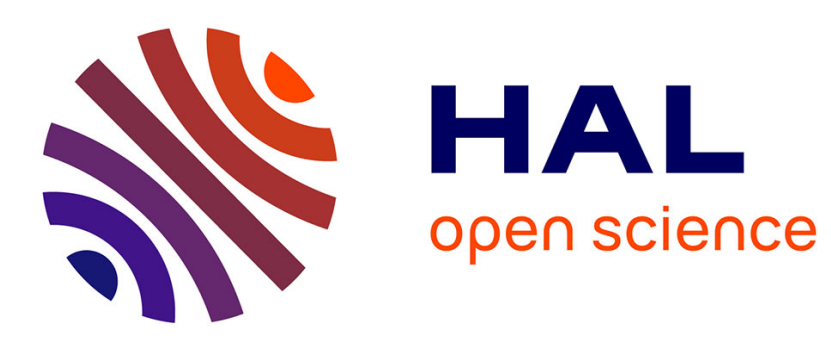

\title{
Effect of inclination on heat transfer coefficient during flow boiling in a mini-channel
}

Thibaut Layssac, Stéphane Lips, Rémi Revellin

\section{To cite this version:}

Thibaut Layssac, Stéphane Lips, Rémi Revellin. Effect of inclination on heat transfer coefficient during flow boiling in a mini-channel. International Journal of Heat and Mass Transfer, 2019, 132, pp.508-518. 10.1016/j.ijheatmasstransfer.2018.12.001 . hal-01951319

\section{HAL Id: hal-01951319 https://hal.science/hal-01951319}

Submitted on 20 Mar 2019

HAL is a multi-disciplinary open access archive for the deposit and dissemination of scientific research documents, whether they are published or not. The documents may come from teaching and research institutions in France or abroad, or from public or private research centers.
L'archive ouverte pluridisciplinaire HAL, est destinée au dépôt et à la diffusion de documents scientifiques de niveau recherche, publiés ou non, émanant des établissements d'enseignement et de recherche français ou étrangers, des laboratoires publics ou privés. 


\title{
Effect of inclination on heat transfer coefficient during flow boiling in a mini-channel
}

\author{
Thibaut Layssac ${ }^{1}$, Stéphane Lips ${ }^{1 *}$, and Rémi Revellin ${ }^{1}$ \\ ${ }^{1}$ Univ Lyon, CNRS, INSA-Lyon, CETHIL UMR5008, F-69621, Villeurbanne, France \\ * mailto:stephane.lips@insa-lyon.fr
}

\begin{abstract}
An experimental study of heat transfer during R245fa flow boiling is carried out in a $1.6 \mathrm{~mm}$ inner diameter circular channel (198 original data points). The test section is composed of a sapphire tube coated with ITO, which enables a total transparency of the evaporator in the visible spectrum. The acquisition of the outer wall temperature field is ensured by means of an infrared camera and the heat transfer coefficient is calculated by means of a local thermal model. The effect of the inclination on the heat transfer is presented and discussed for various vapour qualities and mass velocities and a saturation temperature of $81^{\circ} \mathrm{C}$, corresponding to a Bond number of 4.1. For each experimental condition, the mean heat transfer coefficient is calculated for various inclinations from the vertical downward flow $\left(-90^{\circ}\right)$ to the vertical upward flow $\left(+90^{\circ}\right)$. The variation of the heat transfer coefficient are first presented and analyzed in the horizontal case. The heat transfer coefficient variations with the flow parameters are interpreted in terms of nucleate and convective boiling and these observations are confirmed by the visualisation of the nucleation phenomenon in the evaporator. The inclination has almost no effect on the heat transfer and this lack of effect is finally interpreted in terms of shift between the annular to intermittent flow pattern transition coupled with the nucleate to convective boiling transition.
\end{abstract}

Keywords: flow boiling, mini-channel, inclination angle, heat transfer coefficient, thermography

\begin{tabular}{|c|c|c|c|}
\hline \multicolumn{4}{|c|}{ Nomenclature } \\
\hline \multicolumn{2}{|c|}{ Roman Letters } & \multicolumn{2}{|l|}{ Subscripts } \\
\hline$B d$ & Bond number & $a m b$ & ambient \\
\hline$d$ & diameter (m) & $b b$ & black body \\
\hline E & enhancement factor (-) & $\operatorname{conv}$ & convective \\
\hline$F$ & suppression factor (-) & conv,air & natural convection \\
\hline$F r_{\text {vap }}$ & vapour Froude number & elec & electric \\
\hline$G$ & mass velocity $\left(\mathrm{kg} \cdot \mathrm{m}^{-2} \cdot \mathrm{s}^{-1}\right)$ & $i$ & inner \\
\hline$M$ & molar mass $\left(\mathrm{g} \cdot \mathrm{mol}^{-1}\right)$ & $i w$ & inner wall \\
\hline$P$ & pressure $(\mathrm{Pa})$ & $l$ & linear \\
\hline $\operatorname{Pr}$ & Prandtl number & meas & measured \\
\hline$R_{l}$ & linear thermal resistance $\left(\mathrm{K} . \mathrm{m} . \mathrm{W}^{-1}\right)$ & nuc & nucleate \\
\hline $\operatorname{Re}$ & Reynolds number & $o$ & outer \\
\hline$T$ & temperature $(\mathrm{K})$ & ow & outer wall \\
\hline$x$ & vapour quality (-) & pred & predicted \\
\hline$z$ & abscissa (m) & $r$ & reduced \\
\hline \multicolumn{2}{|c|}{ Greek Letters } & $\mathrm{rad}$ & radiative \\
\hline$\alpha$ & heat transfer coefficient $\left(\mathrm{W} \cdot \mathrm{m}^{-2} \cdot \mathrm{K}^{-1}\right)$ & sat & saturation \\
\hline$\beta$ & inclination angle (rad) & $t p$ & two-phase \\
\hline$\epsilon$ & emissivity (-) & trans & transmitted \\
\hline$\lambda$ & thermal conductivity $\left(\mathrm{W} \cdot \mathrm{m}^{-1} \cdot \mathrm{K}^{-1}\right)$ & & \\
\hline$\rho$ & density $\left(\mathrm{kg} \cdot \mathrm{m}^{-3}\right)$ & & \\
\hline$\sigma_{s b}$ & Stefan-Boltzmann constant $\left(\mathrm{W} \cdot \mathrm{m}^{-2} \cdot \mathrm{K}^{-4}\right)$ & & \\
\hline$\varphi$ & heat flux (W.m²) & & \\
\hline$\Phi_{l}$ & linear heat transfer rate $\left(\mathrm{W} \cdot \mathrm{m}^{-1}\right)$ & & \\
\hline
\end{tabular}




\section{Introduction}

Two-phase flows with phase change are encountered in many industrial applications, especially considering those using thermodynamic cycles. These cycles can be composed of condensers and evaporators whose efficiency depends on the conditions of the two-phase flow occurring inside. Consequently, the geometrical configuration of these applications affects their performance. In inclined configuration, V-shaped condensers are used for refrigerating applications. The miniaturization of the thermodynamic systems may also require inclined geometrical configurations, in the case of embedded Organic Rankine Cycles for example.

Many studies available in the literature deal with the effect of the experimental conditions on the heat transfer in the cases of heated air-water flow, convective condensation or flow boiling. However, as mentioned in the review of Lips and Meyer [1], the large majority of these studies were carried out for horizontal or vertical flows. Moreover, the few studies dealing with the effect of the inclination on the heat transfer which are cited by Lips and Meyer [1] are focusing on a small range of angles, generally near the horizontal orientation.

The studies of Ghajar and Kim [2], Ghajar and Tang [3] but also the one from Vaze and Banerjee [4] were performed with air-water flows in horizontal and upward flows with inclination angles of $2^{\circ}, 5^{\circ}$ and $7^{\circ}$ in a $27.9 \mathrm{~mm}$ inner diameter channel. All these studies show a very strong dependency of the heat transfer coefficient with the inclination angle. In these works, two-phase flows were visualised, which enabled an analysis of the effect of the inclination with the various observed flow patterns. It was shown that the heat transfer coefficient was more sensitive to the inclination in the case of a slug flow pattern, with a relative variation of 50\% depending on the orientation. Empirical correlations were developed to predict the heat transfer coefficient, taking into consideration the effect of the inclination.

These works were recently completed by the studies of Bhagwat and Ghajar $[5,6]$ for the whole range of inclination. They were conducted with air-water flows in a $12.7 \mathrm{~mm}$ inner diameter channel, confirming the strong influence of inclination on heat transfer for low-inertia flows. However, it is shown that the heat transfer is strongly influenced by the inclination not only in the case of an intermittent flow but also with the stratified flows for downward inclinations. In this case, the relative variation of the heat transfer coefficient with the inclination angle may even reach $200 \%$ for a gas superficial Reynolds number of 280.

Since the review of Lips and Meyer [1], an intensification of the studies in both flow condensing and flow boiling under inclined configurations was noticed. The main quantitative results of these studies are summarized in Table 1. For each study, the configuration is specified in terms of fluid, inner diameter, geometry and range of tested inclinations. Three main geometrical configurations may be distinguished: the smooth, the corrugated and the multiple channels evaporator. The results of the studies are presented in terms of maximal relative range of variation of the heat transfer coefficient with the 
angle of inclination. The configuration which enabled this enhanced effect of the inclination is mentioned in terms of optimal angle of inclination $\beta\left(\alpha_{\max }\right)$, corresponding to the maximal heat transfer coefficient in this configuration. The Bond number and the vapour Froude number (definition of Cioncolini and Thome [7]) corresponding to this configuration are calculated, the lowest values of these two dimensionless numbers being presented in red while the highest ones being presented in green:

$$
\begin{gathered}
B d=\frac{g\left(\rho_{\text {liq }}-\rho_{\text {vap }}\right) d_{i}{ }^{2}}{\sigma} \\
F r_{\text {vap }}=\frac{\frac{x G}{\sqrt{\rho_{\text {vap }}}}}{\sqrt{g\left(\rho_{\text {liq }}-\rho_{\text {vap }}\right) d_{i}}}
\end{gathered}
$$

The Bond number is often used in the literature to make the distinction between mini and macro-channel behaviours. Even if the definition of this kind of criteria is still an open question in the literature, the value of the transition Bond number usually varies from 1 to 4 [8]. The range of variation of the calculated Bond numbers show that the large majority of studies were carried out under macro-channels. As it was observed for heated air-water flows, all the studies about the effect of inclination on the heat transfer coefficient during flow boiling showed a higher dependency of the heat transfer for low-inertia flows, corresponding to low vapour Froude numbers. However, it is observed a relatively high dispersion of the inclination angles that enables to maximize the heat transfer coefficient compared to the little number of studies which were noticed. The effect of inclination on heat transfer, although more recently studied, is not well known and strongly depends on the experimental parameters.

The interpretation and comparison of the results of the three configurations (condensation, gas-liquid flow and flow boiling) must rely on a physical analysis as the heat transfer phenomena can be different for each case. While mostly convective film heat transfer occurs in the case of heated air-water and condensation, nucleate boiling heat transfer is also present during flow boiling. For this reason, due to the coupling between the two heat transfer modes, effect of gravity on flow boiling may be quite different. The comparison between the various configurations may be possible in the case of high vapour quality flows, when convective heat transfer is largely dominant. In addition, a comparison with condensing and heated air-water flows for low vapour qualities may bring a highlight about the effect of convective boiling when nucleate boiling is dominant.

The present paper aims at bringing new insights on the impact of inertial, capillary and gravitational forces on the heat transfer through an experimental study of the effect of inclination angle on heat transfer during flow boiling in a mini-channel. The dependency, or independency, of the heat transfer on the inclination angle is used as a tool to identify the main heat transfer phenomena involved during flow boiling depending on the experimental conditions. The study is based on a test campaign carried out on the effect of the inclination on R245fa flow boiling in a transparent evaporator. The experimental setup and the experimental database are presented in the first section. The effects of the two-phase flow 
parameters on the heat transfer coefficient are presented in the second section. Finally, the comparison of the experimental results with asymptotic models available in the literature enables to identify the importance of each heat transfer phenomenon and thus to better understand and explain the experimental results.

\section{Test bench description and heat transfer coefficient measurement method}

\subsection{Description of the test section}

The current test section has to ensure the R245fa flow boiling in various conditions, in terms of mass velocity, vapour quality and inclination while the saturation temperature is controlled. The control of the saturation temperature and the mass velocity are ensured by the test bench previously designed by Layssac et al. [23] and presented in Figure 1. The study of the effect of the inclination on the R245fa flow boiling heat transfer is carried out by the mean of an inclinable test section whose schematic is presented in Figure 2. This test section is made of an inclinable aluminium frame, which enables the study of flow boiling for the whole range of inclination. The frame supports the hydraulic loop, which is composed of a preheater and a transparent evaporator. The $2000 \mathrm{~mm}$ stainless steel preheater is heated by Joule effect, which enables the control of the vapour quality at the inlet of the evaporator. Due to the low mass velocities and the low heat rates $(<15 \mathrm{~W})$ which were considered in the present study, the calculation of the vapour quality required to take into consideration the preheater and evaporator heat losses. The global heat losses for both these components were obtained by calculating the thermal resistance associated to the transmission of the heat flux to the fluid and the one associated to the heat losses to the surroundings. The final error on the energy balance was less than 5\%. Layssac [24] provides more details about the methodology to calculate the heat losses.

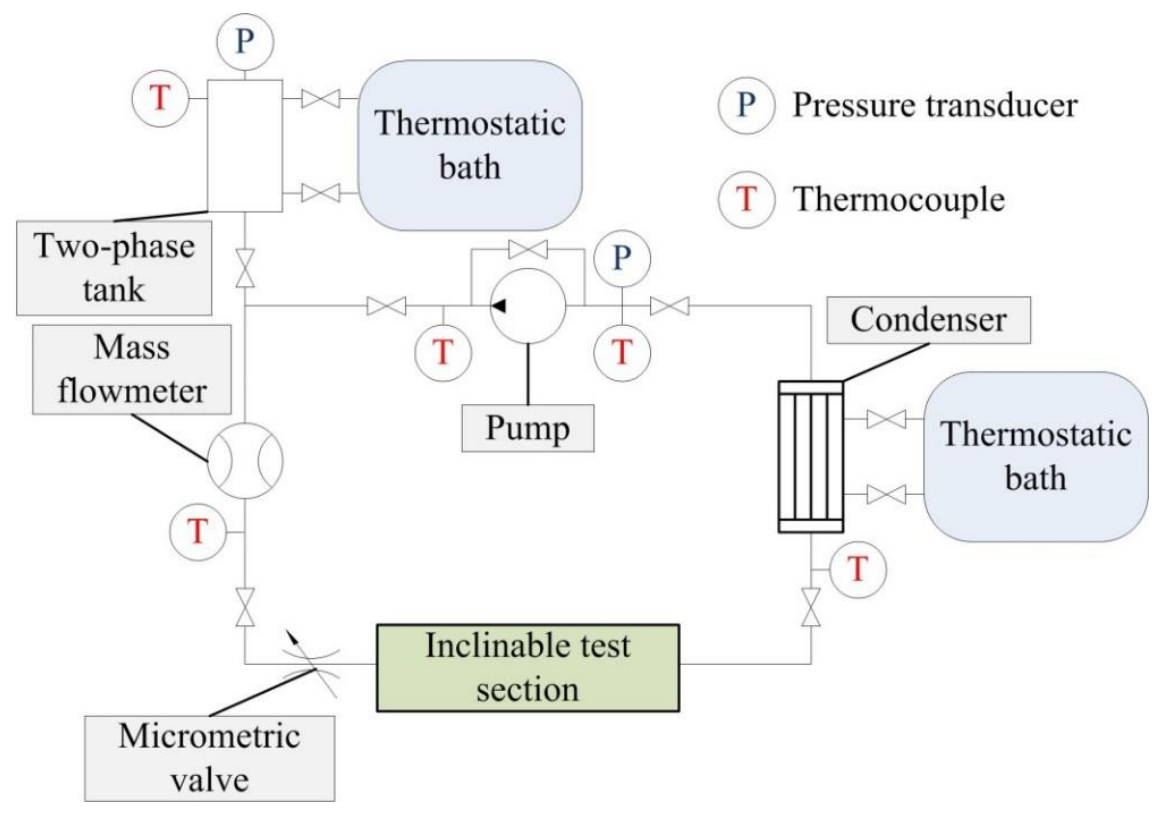

Figure 1: Schematic of the test bench 
Table 1: Optimal configurations and ranges of variation of the heat transfer coefficient for the studies from the literature

Optimal configuration

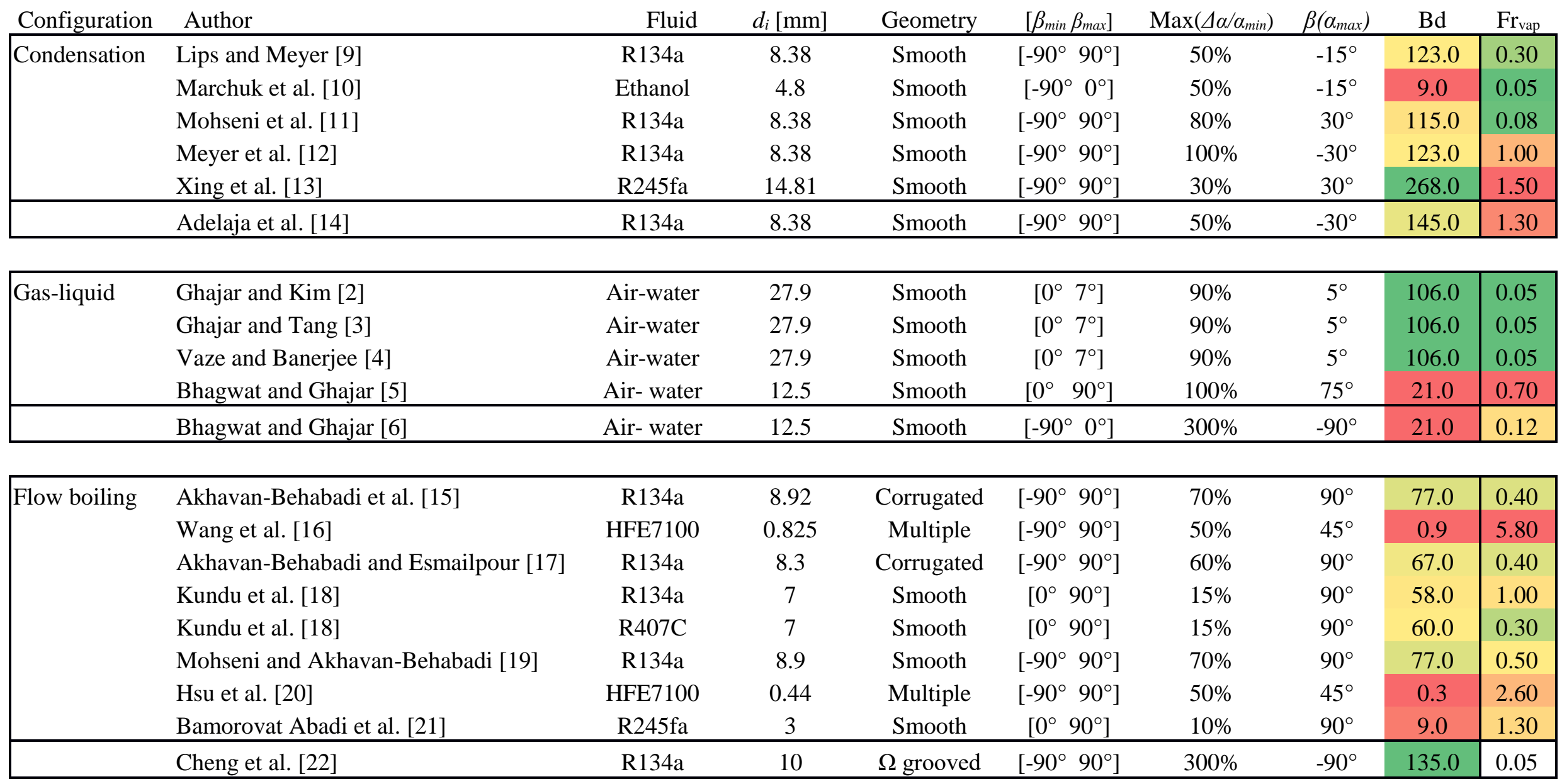




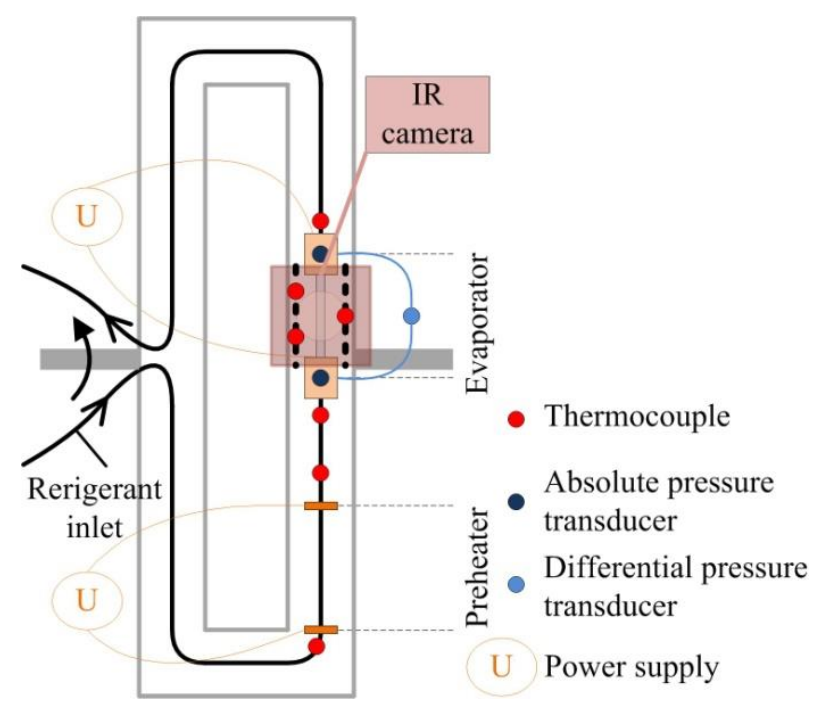

Figure 2: Schematic of the inclinable test section (top view)

The study of the effect of the inclination on the R245fa flow boiling heat transfer is carried out with the transparent evaporator and the IR camera (Figure 3). The evaporator is composed of a $200 \mathrm{~mm} \pm 1.0 \mathrm{~mm}$ long sapphire tube which is externally coated with a transparent layer of indium-tin-oxide (ITO). The hydraulic diameter of the evaporator is equal to $1.6 \mathrm{~mm} \pm 0.15 \mathrm{~mm}$. In the present study, the resistivity of the ITO coating is equal to $450 \Omega \pm 10 \Omega$ corresponding to a thickness equal to about $1 \mu \mathrm{m}$. The choice of the ITO coating thickness was motivated by a trade-off between its opacity and its resistivity. Moreover, due to the variability of the ITO resistivity with the temperature and aging, both supplied tension and intensity have to be measured during the test campaign. This setup enables the heating of a transparent evaporator by Joule effect.

A global thermal model is necessary to calculate the vapour quality at the middle of the evaporator because the evaporator is not thermally insulated. The choice of avoiding thermal insulation of the evaporator is mainly motivated by the infrared acquisition which would require a harder radiative model with insulation [25]. As for the preheater, the error on the energy balance in the evaporator is less than $10 \%$. The two energy balances result in a mean vapour quality uncertainty of \pm 0.05 in the worst case. The control of the saturation conditions is ensured at the inlet of the evaporator with an absolute pressure transducer whose uncertainty is 0.07 bar and a $\mathrm{K}$ type thermocouple whose uncertainty is $\pm 0.25 \mathrm{~K}$. The latter is the combination between the uncertainty of calibration $(0.1 \mathrm{~K})$ and the estimation of the bias measurement due to the location of the thermocouples on the test set-up. This bias is due to the difficulty to measure the temperature as close as possible to the inlet and outlet of the test section, but avoiding the peek junctions in which heat losses are observed (Figure 3b). The mass flow rate in the test section is measured by means of a Micro Motion Coriolis type mass flowmeter with an accuracy of $0.1 \%$. 


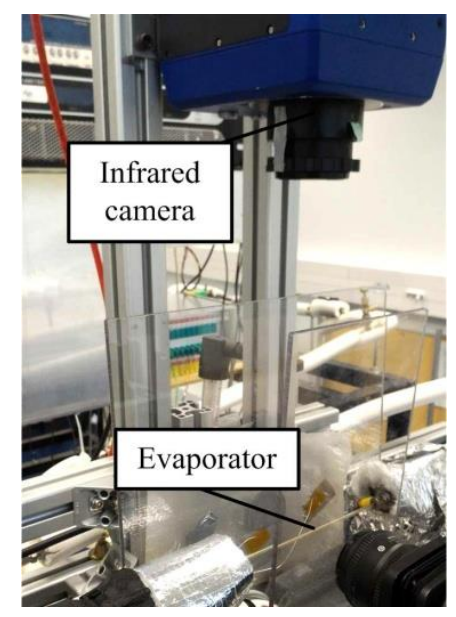

a) Photo

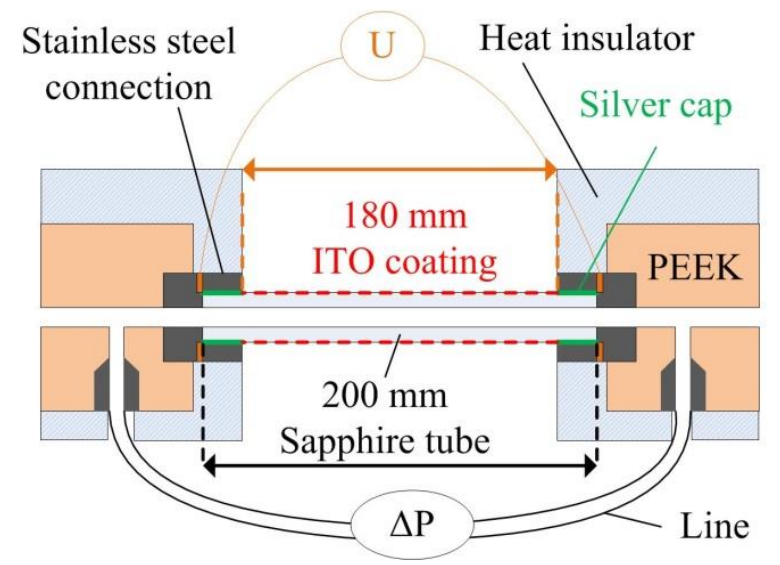

b) Schematic

Figure 3: Photo (a) and schematic (b) of the evaporator

\subsection{Infrared measurement}

For each condition of mass velocity, vapour quality and inclination angle, the mean heat transfer coefficient at the centre of the evaporator is obtained by means of an IR camera FLIR SC 7000 and a Matlab post-processing. The IR camera is located above the sapphire tube in the case of a horizontal orientation, at a distance of $300 \mathrm{~mm}$ from the tube (Figure 4). With this distance and considering a resolution of $512 \times 640$ pixels, the maximal zoom enables a precision characterized by a conversion factor of 10 pixels $/ \mathrm{mm}$. The electric signal is then coded in 14 bits, which enables to obtain a frame with grayscale values between 0 and 16383. These values are converted into black body temperatures with the software Altair as shown in Figure 5. The rough variations of the black body temperature in the orthogonal direction to the flow are mainly due to the directional emissivity of the ITO, being higher near an angle of emission of $90^{\circ}$. 


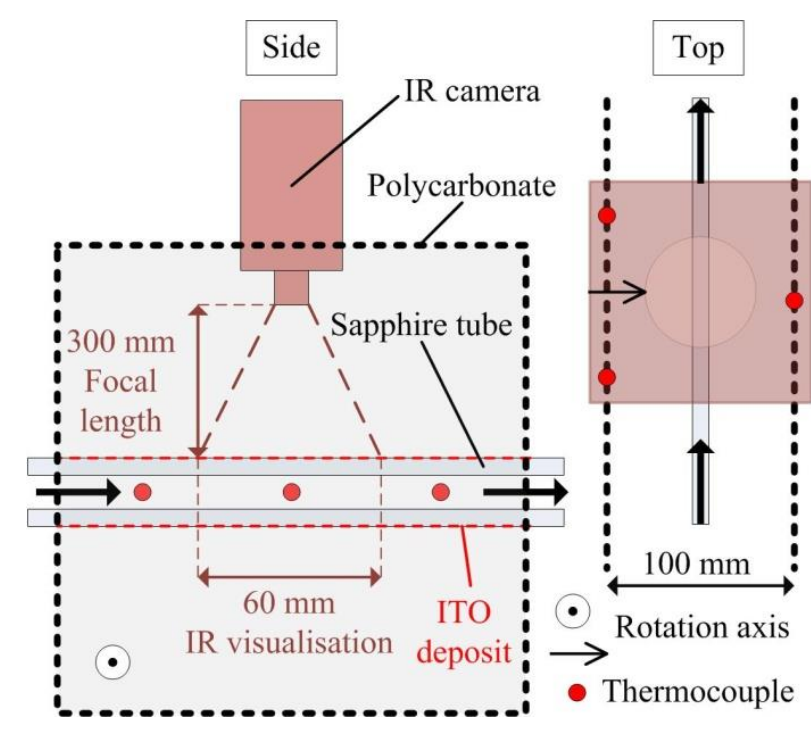

Figure 4: Top and side views of the IR test section

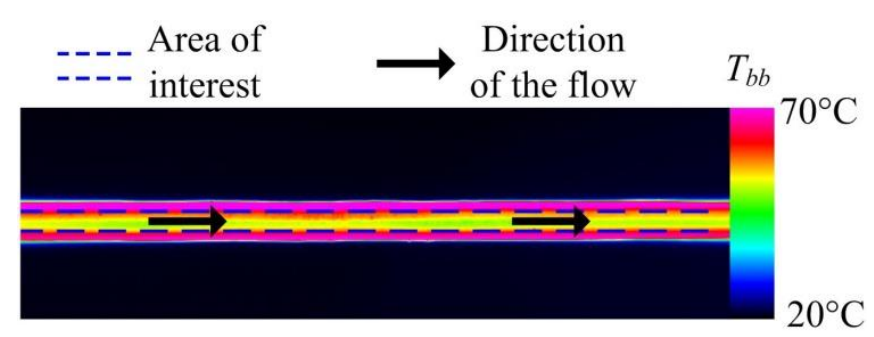

Figure 5: Black body temperature field

Consequently, longitudinal profiles of black body temperature are obtained by considering the average of the black body temperature field for orthoradial angles of the sapphire tube between $60^{\circ}$ and $120^{\circ}$, which corresponds to the region between the two blue lines on Figure 5. Calculating a mean value is necessary to limit the effects of the noises of measurement and the variations of ITO coating thickness.

Considering the direct emission of the ITO coating and the reflexion of the environment of the tube, the digital level $D L$ of each pixel of the camera is a function of the sensitivity of the IR camera sensors $F$, the outer wall and ambient temperatures $T_{o w}$ and $T_{a m b}$ respectively and the emissivity of the ITO coating:

$$
D L=K \sigma_{s b}\left[\epsilon F\left(T_{o w}\right) T_{o w}^{4}+(1-\epsilon) F\left(T_{a m b}\right) T_{a m b}^{4}\right]
$$

with $K$ a multiplying factor and $\sigma_{s b}$ the Stefan-Botzmann constant.

The digital level may also be expressed by considering the black body temperature $T_{b b}$ given by the infrared camera, corresponding to a case where there is no reflexion of the ITO coating:

$$
D L=K \sigma_{s b} F\left(T_{b b}\right) T_{b b}^{4}
$$

The equalisation of equations ( 3 and ( 4 enables the following expression of the outer wall temperature: 


$$
T_{o w}=\left[\frac{1}{F\left(T_{o w}\right)}\left[F\left(T_{a m b}\right) T_{a m b}^{4}+\frac{1}{\epsilon}\left[F\left(T_{b b}\right) T_{b b}^{4}-F\left(T_{a m b}\right) T_{a m b}^{4}\right]\right]\right]^{\frac{1}{4}}
$$

The ambient temperature $T_{a m b}$ is given by the three thermocouples set up on the polycarbonate plates located on each side of the test section. The sensitivity of the IR camera sensors $F(T)$ is given by the manufacturer FLIR and was tested in laboratory. The emissivity of the ITO coating is not known a priori and a calibration is then needed. The calibration enables getting the variations of the ITO emissivity with the outer wall temperature and the abscissa of the tube due to the coating heterogeneity. To obtain this emissivity, an outer wall temperature is imposed by heating the tube with a high velocity liquid single-phase flow and is calculated by a local thermal model. For each condition of known outer wall temperature $T_{o w}$, the emissivity $\epsilon$ may be calculated by measuring the corresponding ambient temperature $T_{a m b}$ and black body temperature $T_{b b}$ :

$$
\epsilon\left(T_{p e}\right)=\frac{F\left(T_{b b}\right) T_{b b}^{4}-F\left(T_{a m b}\right) T_{a m b}^{4}}{F\left(T_{o w}\right) T_{o w}^{4}-F\left(T_{a m b}\right) T_{a m b}^{4}}
$$

Profiles of ITO coating emissivity are given for outer wall temperatures of $70^{\circ} \mathrm{C}, 80^{\circ} \mathrm{C}$ and $90^{\circ} \mathrm{C}$ in Figure 6 . The variations of the emissivity with the abscissa are due to the heterogeneity of the ITO coating. Because of this heterogeneity, the outer wall temperature has to be calculated for each abscissa of the IR visualisation section to be able to obtain the mean heat transfer coefficient for each experimental condition. The outer wall temperature uncertainty is $0.4^{\circ} \mathrm{C}$ for an ITO coating temperature of $81^{\circ} \mathrm{C}$ and an ambient temperature of $25^{\circ} \mathrm{C}$. This value strongly increases for lower temperatures due to the higher relative part of the radiation flux coming from the environment and the relatively low emissivity of the ITO coating. Consequently, the experiments were carried out with a unique saturation temperature of $81^{\circ} \mathrm{C}$.

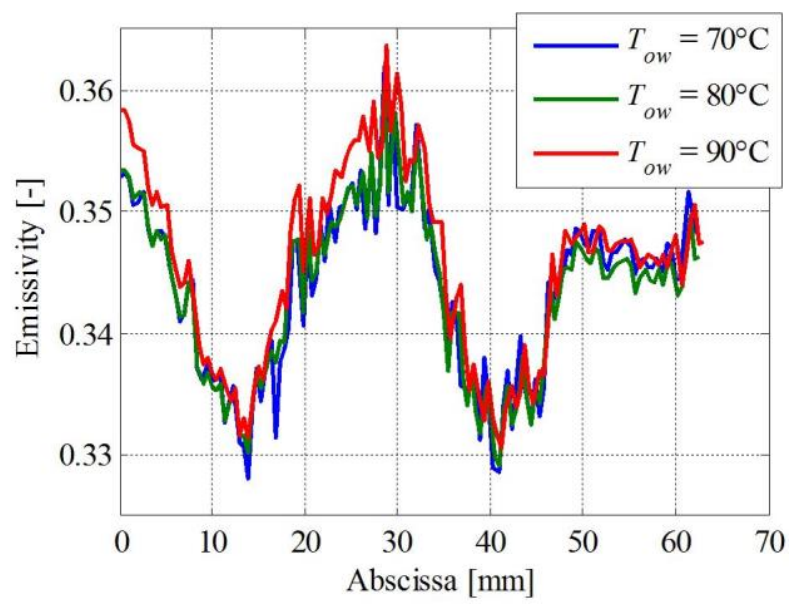

Figure 6: Variations of the ITO deposit emissivity with abscissa for sapphire outer wall temperature of $70^{\circ} \mathrm{C}, 80^{\circ} \mathrm{C}$ and $90^{\circ} \mathrm{C}$ 
The heterogeneity of the ITO coating may affect the homogeneity of the imposed heat flux. However, when a heat flux of $13.5 \mathrm{~kW} \cdot \mathrm{m}^{-2}$ was imposed on the test section, it has been observed a relatively low heterogeneity of the ITO coating temperature as it is shown in the example of Figure 7. The mean standard deviation of the observed distributions for the whole experimental temperature data is $0.25 \mathrm{~K}$ and is thus negligible compared to the uncertainty of the wall temperature measurement obtained by the IR camera $(0.4 \mathrm{~K})$. The heat flux can thus be considered as homogeneous along the test section. It may be reported that a heat flux of $13.5 \mathrm{~kW} / \mathrm{m}^{2}$ also leads to a maximal variation of the vapour quality of 0.08 on the infrared section, which also ensures the homogeneity of the heat transfer coefficient inside the tube.

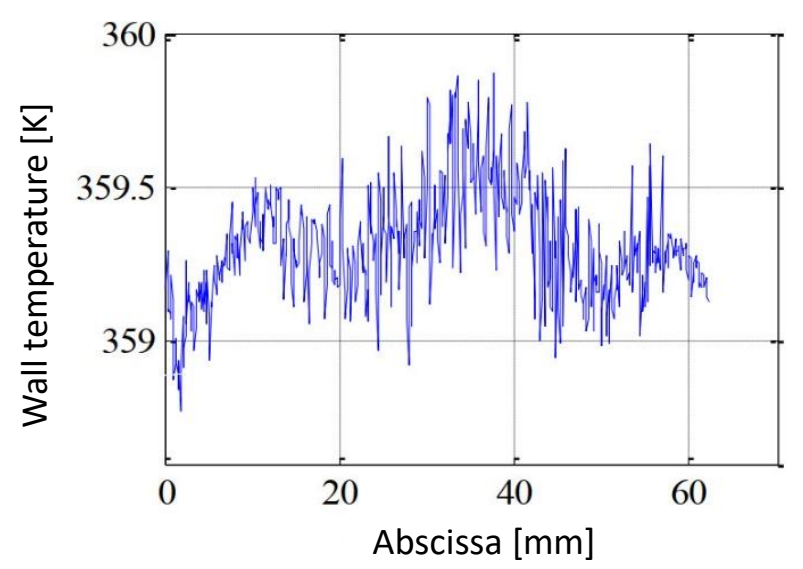

Figure 7: Example of variations of the ITO coating temperature

$$
\left(G=150 \mathrm{~kg} \cdot \mathrm{m}^{-2} \cdot \mathrm{s}^{-1}, x=0.3, \varphi_{\text {trans }}=13.5 \mathrm{~kW} \cdot \mathrm{m}^{-2}\right)
$$

\subsection{Heat transfer data reduction}

Outer wall temperature being calculated along the IR visualisation section, it is possible to determine the heat transfer coefficient for each abscissa along this section by a local thermal model. The calculation of the local heat transfer $\alpha$ requires the knowledge of three local quantities: the inner wall temperature $T_{i w}$, the saturation temperature $T_{\text {sat }}$ and the heat flux transfered to the saturated fluid $\varphi_{\text {trans }}$. Considering a homogenous heat flux, the expression of the heat transfer coefficient at the abscissa $z$ is:

$$
\alpha=\frac{\varphi_{\text {trans }}}{T_{i w}(z)-T_{\text {sat }}(z)}
$$

As previously mentioned, the saturation temperature is known at the inlet of the evaporator. Additionally, the pressure drop is measured in the evaporator, which enables the calculation of the saturation temperature at the abscissa $z$, considering a linear evolution of the saturation pressure in the evaporator. This assumption is valid because of the low vapour quality variation inside the test section combined to the fact that the data were obtained in conditions for which the evolution of the pressure gradient is monotonic (far from the its maximum). 
In the present test section, the heat flux transfered to the fluid and the inner wall temperature are not measured directly. As a result, a local thermal model is required to calculate them, considering the heat losses of the evaporator (Figure 8). The linear thermal resistances and linear energy flux taken into account in the thermal model are represented in Figure 9.

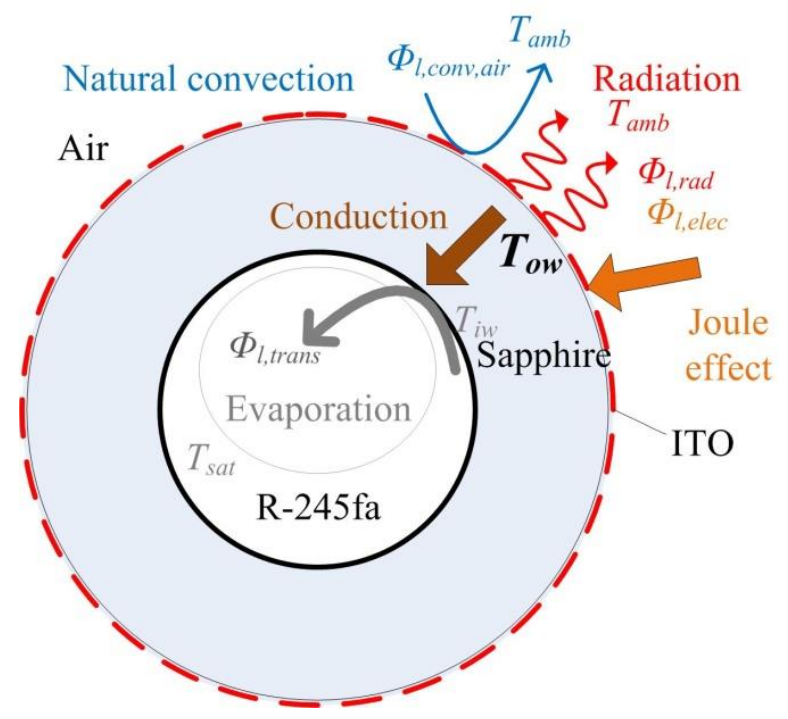

Figure 8: Thermal model at abscissa $z$

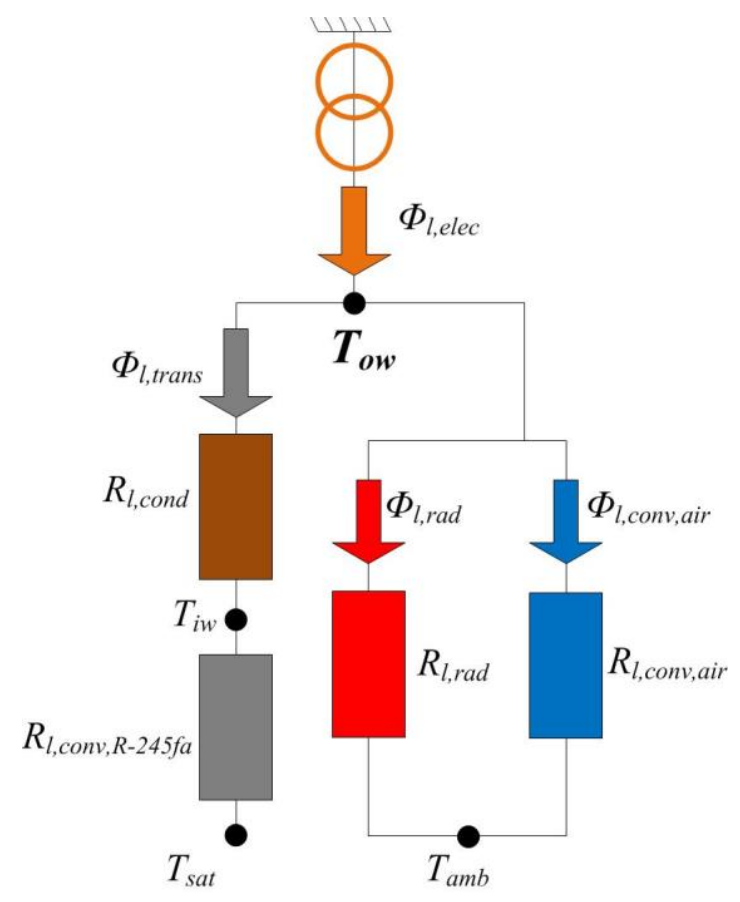

Figure 9: Electrical equivalent circuit of the local thermal model

This model takes into consideration the sapphire conduction and the heat losses by radiation and by natural convection, which results into the following expressions of the inner wall temperature and the linear heat rate transferred to the flow: 
with $T_{o w}=T_{i w}-R_{l, \text { cond }} \Phi_{l, \text { trans }}$

$$
\Phi_{l, \text { trans }}=\Phi_{l, \text { elec }}-\left(\frac{1}{R_{l, \text { rad }}}+\frac{1}{R_{l, \text { conv,air }}}\right)\left(T_{o w}-T_{a m b}\right)
$$

where $R_{l, c o n d}, R_{l, \text { rad }}$ and $R_{l, c o n v, \text { air }}$ are the linear thermal resistances of conduction in the sapphire, radiation and natural convection respectively. $\Phi_{l, e l e c}$ is the linear heat flux coming from Joule effect in the ITO coating.

The linear thermal resistance of conduction is calculated by considering a radial conduction in the sapphire:

$$
R_{l, \text { cond }}=\frac{\ln \left(\frac{d_{o}}{d_{i}}\right)}{2 \pi \lambda_{\text {sapphire }}}
$$

where $d_{o}$ and $d_{i}$ are respectively the outer and the inner diameters of the sapphire tube and $\lambda_{\text {sapphire }}$ is its thermal conductivity. The value of the thermal conductivity of the sapphire is taken at the saturation temperature.

The linear resistance of radiation is calculated with the emissivity of the ITO coating:

$$
R_{l, r a d}=\left[\epsilon \sigma_{s b} \pi d_{o}\left(T_{o w}^{2}+T_{a m b}^{2}\right)\left(T_{o w}+T_{a m b}\right)\right]^{-1}
$$

where $\sigma_{s b}$ is the constant of Stefan-Boltzmann.

The linear resistance of natural convection due to the air circulation around the tube is obtained by calculating the corresponding heat transfer coefficient coming from the correlation of Churchill and Chu [26]:

$$
R_{l, \text { conv, air }}=\frac{1}{\alpha_{\text {Churchill }} \pi d_{o}}
$$

The relative uncertainties of the linear thermal resistances of conduction, radiation and natural convection are respectively $15 \%, 10 \%$ and $25 \%$ while less than $10 \%$ of the heat flux is lost by radiation and natural convection. Consequently, considering the uncertainties from the local thermal model and the uncertainty of the outer wall temperature, the mean relative error of the heat transfer coefficient is $30 \%$ for the whole range of experimental conditions. The test rig performance was validated for singlephase flow configurations (both friction and heat transfer). The results are not presented in the present paper for a sake of clarity, but are available in [24].

\section{$2.4 \quad$ New experimental data points}

A test campaign was carried out with a saturation temperature of $81^{\circ} \mathrm{C}$ with a heat flux of $13.5 \mathrm{~kW} \cdot \mathrm{m}^{-2}$. The choice of these parameters was motivated by considerations about the heat transfer coefficient uncertainty. For each set of mass velocity and vapour quality, the mean heat transfer coefficient along the infrared visualisation section was calculated for inclination angles of $-90^{\circ}, 60^{\circ},-45^{\circ},-30^{\circ},-15^{\circ}, 0^{\circ}$, 
$15^{\circ}, 30^{\circ}, 45^{\circ}, 60^{\circ}$ and $90^{\circ}$. The ranges and the fluctuations of the experimental parameters for each angle of inclination are summarised in Table 2. The fluctuations are calculated as the mean standard deviation of each series of experiment made with a given mass velocity and vapour quality.

Table 2: Ranges of experimental parameters

\begin{tabular}{lcc} 
& Range & Fluctuations \\
\hline Number of data points & 198 & - \\
Heat flux & $\varphi=13.5 \mathrm{~kW} \cdot \mathrm{m}^{-2}$ & $0.2 \mathrm{~kW} \cdot \mathrm{m}^{-2}$ \\
Hydraulic diameter $d$ & $1.6 \mathrm{~mm}$ & - \\
Saturation temperature $T_{\text {sat }}$ & $80.9^{\circ} \mathrm{C}$ & $0.2^{\circ} \mathrm{C}$ \\
Mass velocity $G$ & $150-300 \mathrm{~kg} \cdot \mathrm{m}^{-2} \cdot \mathrm{s}^{-1}$ & $3 \mathrm{~kg} \cdot \mathrm{m}^{-2} \cdot \mathrm{s}^{-1}$ \\
Vapour quality $x$ & $0.03 \rightarrow 0.85$ & 0.01 \\
Inclination angle $\beta$ & $-90^{\circ} \rightarrow 90^{\circ}$ & $<0.5^{\circ}$ \\
\hline
\end{tabular}

The heat flux was chosen sufficiently low to avoid a too large variation of vapour quality in the test section. With a mass velocity of $150 \mathrm{~kg} \cdot \mathrm{m}^{-2} \cdot \mathrm{s}^{-1}$, a heat flux of $13.5 \mathrm{~kW} \cdot \mathrm{m}^{-2}$ results in a difference of vapour quality lower than 0.15 between the inlet and the outlet of the evaporator. The vapour quality is then calculated at the middle of the evaporator.

The current ranges of experimental parameters focus on the low inertia driven two-phase flow. This is motivated by the fact that the inclination affects the two-phase flow when the gravity forces are strong compared to inertia forces, which corresponds to a low vapour Froude number. Additionally, the configuration of the study is also characterized by a low diameter compared to the large majority of the previous studies dealing with the effect of inclination on two-phase flows (Table 1). In the present study, the Bond number is equal to 4.2, which corresponds to the case of a mini-channel. However, the effect of inclination on the heat transfer coefficient in the case of flow boiling was still observed with microchannels $(\mathrm{Bd}<1)[16,20]$.

\section{Results and discussion}

\subsection{Effect of the flow parameters on the heat transfer coefficient}

\section{Horizontal case}

Figure 10 presents the results of the test campaign in terms of variations of the heat transfer coefficient with the vapour quality in the case of horizontal orientation $\left(\beta=0^{\circ}\right)$. Results are presented for mass velocities of $150 \mathrm{~kg} \cdot \mathrm{m}^{-2} \cdot \mathrm{s}^{-1}$ (red markers) and $300 \mathrm{~kg} \cdot \mathrm{m}^{-2} \cdot \mathrm{s}^{-1}$ (blue markers). Note that the relative uncertainty on the measurements increases when the heat transfer coefficient increases because of the lower temperature difference between the wall and the fluid when the vapour quality increases. 
For both mass velocities, the heat transfer coefficient increases with the vapour quality. However, the increase is more pronounced in the case of a mass velocity of $300 \mathrm{~kg} \cdot \mathrm{m}^{-2} \cdot \mathrm{s}^{-1}$ than for a mass velocity of $150 \mathrm{~kg} \cdot \mathrm{m}^{-2} \cdot \mathrm{s}^{-1}$. Despite the important measurement uncertainties, it can be concluded that mass velocity does not affect the heat transfer coefficient for a vapour quality lower than 0.4. A small effect probably exists for higher vapour qualities. All these observations are consistent with the transition between the nucleate boiling and the convective boiling heat transfer mode. With a mass velocity lower than 0.4 , heat transfer is insensitive to both vapour quality and mass velocity because nucleate boiling is dominant. For higher vapour qualities, convective boiling becomes dominant and the heat transfer coefficient is thus increased by the vapour phase inertia.

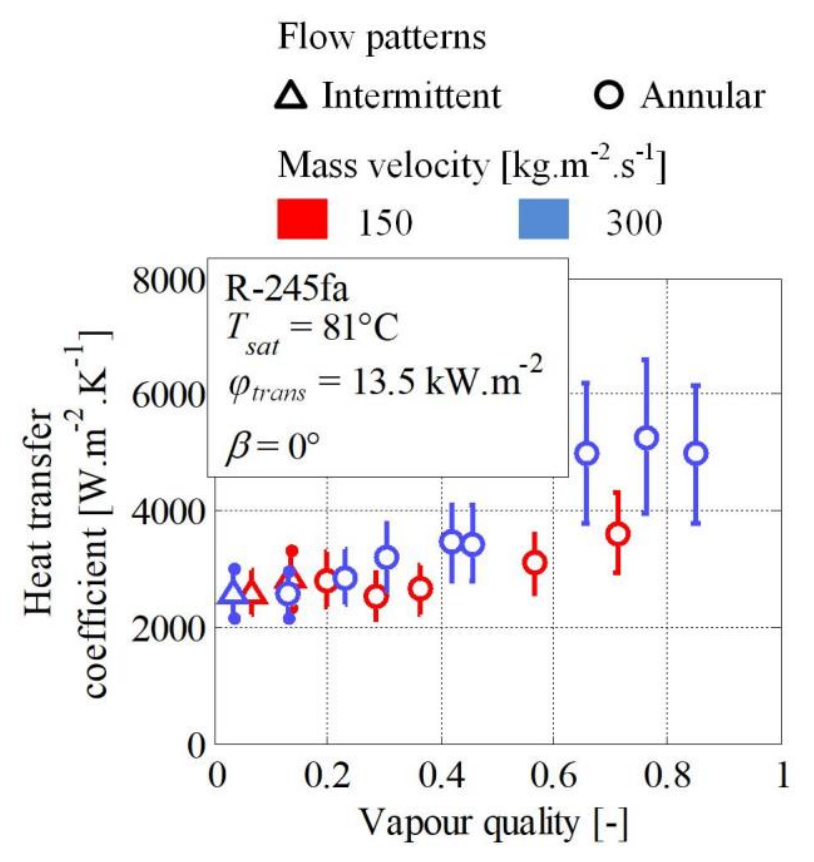

Figure 10: Variations of the heat transfer coefficient with the vapour quality for a mass velocity of

$$
150 \mathrm{~kg} \cdot \mathrm{m}^{-2} \cdot \mathrm{s}^{-1} \text { (red) and } 300 \mathrm{~kg} \cdot \mathrm{m}^{-2} \cdot \mathrm{s}^{-1} \text { (blue) }
$$

The transitions between the two heat transfer modes are observed in the evaporator as it is presented in Figure 11 in the case of horizontal flows. For both mass velocities, with a vapour quality of 0.06 , the flow is intermittent and a large amount of little bubbles coming from the nucleation are observed. When the vapour quality increases $(x=0.4)$, the flow becomes annular but some bubbles coming from the inner wall are still observed. Some of them are highlighted with circles on the figures. These bubbles are more present in the case of a lower mass velocity of $150 \mathrm{~kg} \cdot \mathrm{m}^{-2} \cdot \mathrm{s}^{-1}$. With a vapour quality of 0.7 , the liquid film becomes thinner and the wall superheat becomes lower. Nucleation at the wall clearly decreases in terms of intensity for $\mathrm{G}=150 \mathrm{~kg} \cdot \mathrm{m}^{-2} \cdot \mathrm{s}^{-1}$ and even disappeared for $\mathrm{G}=300 \mathrm{~kg} \cdot \mathrm{m}^{-2} \cdot \mathrm{s}^{-1}$ since no little bubbles are observed around the annular vapour core in the evaporator. The effect of the inclination angle on the flow pattern with and without heat flux is discussed in details in [27] and it appears that the present observations do not depend on the inclination angle. 
$G=150 \mathrm{~kg} \cdot \mathrm{m}^{-2} \cdot \mathrm{s}^{-1}$
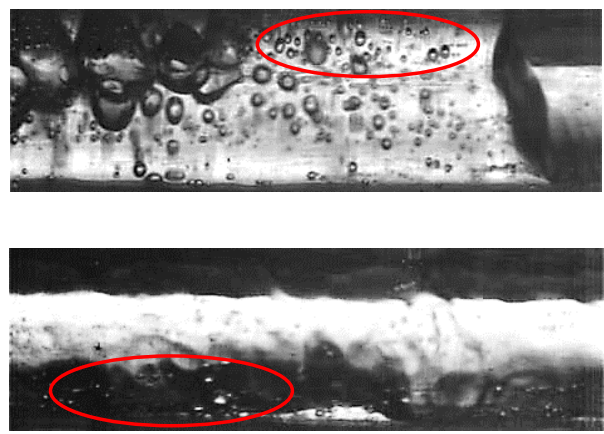

$x=0.7$

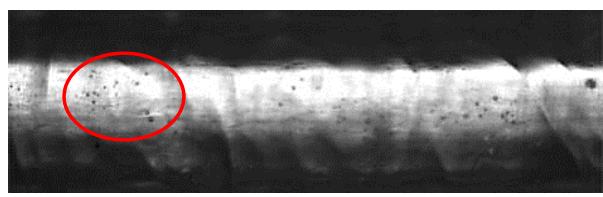

$G=300 \mathrm{~kg} \cdot \mathrm{m}^{-2} \cdot \mathrm{s}^{-1}$
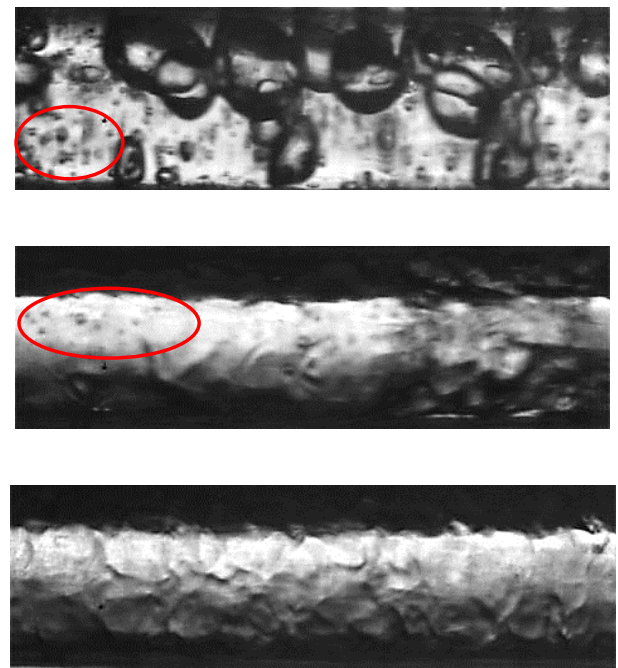

Figure 11: Pictures of the flow in the evaporator for various mass velocities and vapour qualities ( $\varphi_{\text {trans }}=13.5 \mathrm{~kW} \cdot \mathrm{m}^{-2}$ and $\beta=0^{\circ}$ ). The circles highlight area with bubbles due to the nucleate boiling.

\section{Effect of inclination}

As it was shown in the literature [2], the heat transfer coefficient may be strongly sensitive to the inclination angle, mainly due to the effect of the gravity forces on the low-inertia flow patterns, such as stratified or intermittent flows. An example of evolution of the heat transfer coefficient as a function of the inclination angle is presented on Figure 12 for a mass velocity of $150 \mathrm{~kg} \cdot \mathrm{m}^{-2} \cdot \mathrm{s}^{-1}$ and a vapour quality of 0.54 . The range of variation of the heat transfer coefficient is about $20 \%$ for a mean uncertainty of $15 \%$. Consequently, the inclination effect is very low.

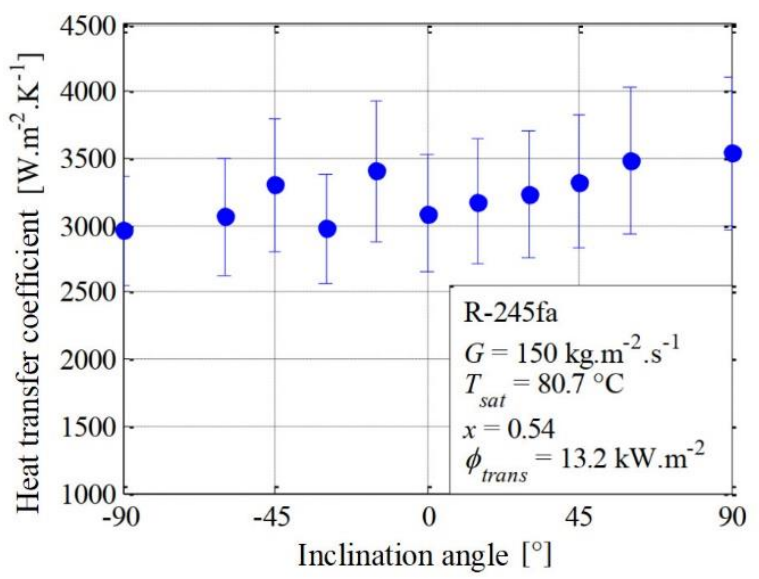

Figure 12: Inclination effect on the heat transfer coefficient for $G=150 \mathrm{~kg} \cdot \mathrm{m}^{-2} \cdot \mathrm{s}^{-1}$ and $x=0.54$ 
The example of Figure 12 actually corresponds to the maximum variation of heat transfer coefficient for the whole set of experiments. Figure 13 presents the variation of the heat transfer coefficient with the vapour quality for various inclination angles and mass velocities of $150 \mathrm{~kg} \cdot \mathrm{m}^{-2} \cdot \mathrm{s}^{-1}$ and $300 \mathrm{~kg} \cdot \mathrm{m}^{-2} \cdot \mathrm{s}^{-1}$. Although mass velocity and vapour quality affect the heat transfer coefficient, it does not seem impacted by the inclination, whatever the experimental conditions, considering its relative uncertainty in the present study.

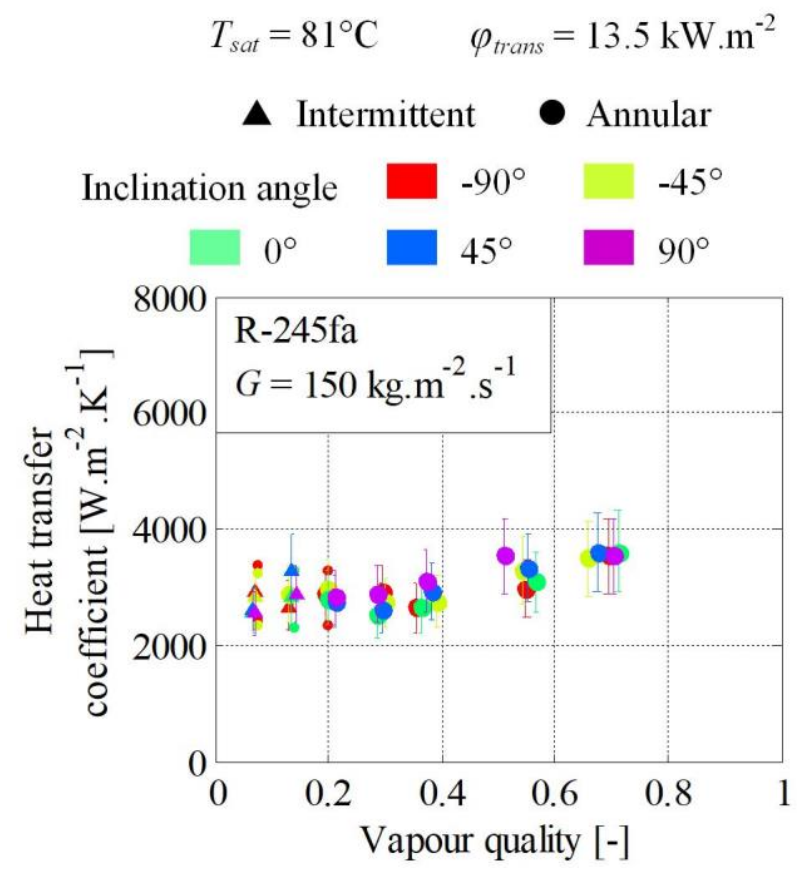

a) $G=150 \mathrm{~kg} \cdot \mathrm{m}^{-2} \cdot \mathrm{s}^{-1}$

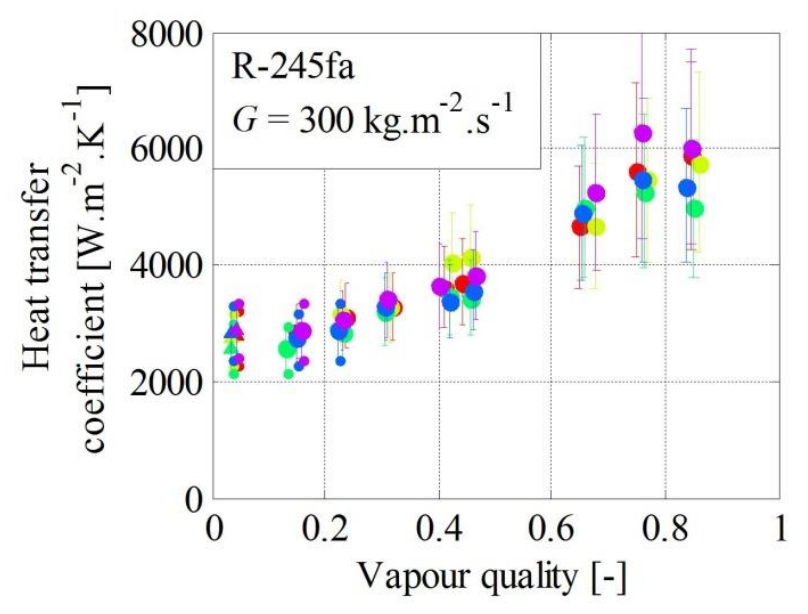

b) $G=300 \mathrm{~kg} \cdot \mathrm{m}^{-2} \cdot \mathrm{s}^{-1}$

Figure 13: Variations of the heat transfer coefficient with the vapour quality for inclination angles of $-90^{\circ},-45^{\circ}, 0^{\circ}, 45^{\circ}$ and $90^{\circ}$ with mass velocities of $150 \mathrm{~kg} \cdot \mathrm{m}^{-2} \cdot \mathrm{s}^{-1}$ (a) and $300 \mathrm{~kg} \cdot \mathrm{m}^{-}$ ${ }^{2} \cdot \mathrm{s}^{-1}(\mathrm{~b})$ 
The lack of inclination effect seems to be consistent with the observations of the literature as it is shown in Figure 14. The results are presented in terms of relative variation of the heat transfer coefficient with the inclination angle as a function of the vapour only Froude number for each operating condition of mass velocity, vapour quality, temperature saturation and heat flux. The relative variation of the heat transfer coefficient is defined as the difference between the maximum and minimum heat transfer coefficient divided by the minimum heat transfer coefficient when only the inclination angle varies. These results come from the studies which were made at least under vertical upward and downward configurations to be able to compare the amplitudes of variations of the heat transfer coefficient. Other indicators could be chosen, but the present one enables to maximise the inclination effect and thus to highlight the importance of the gravitational forces on the heat transfer. The results of the experiments made with macro-channels $(\mathrm{Bd}>60)$ show a strong dependency of the heat transfer coefficient with the inclination for low vapour Froude number, corresponding to low-inertia cases. This dependency decreases with the vapour Froude number. In the case of micro-channels $(\mathrm{Bd}<1)$, the relative variations of the heat transfer coefficient with the inclination do not depend on the vapour Froude number. This difference of behaviour may be due to the different phenomenology between micro and macro-channel two-phase flows. In macro-scale $[15,17,19,22]$, the two-phase flow is mainly annular or stratified while in micro-scale slug flows were observed $[16,20]$. The effect of inclination may be interpreted in terms of partial dry-out of the upper part of the tube in macro-scale. In micro-scale, the stronger effect of capillarity causes the dry-out of the upper part of the tube to strongly decay. In the present case, the intermediate scale $(\mathrm{Bd}=4.1)$ results in a low effect of the inclination which seems to be a limit case of the two observed behaviours. This lack of inclination effect may be also highlighted by considering the relative importance of nucleate and convective boiling in the heat transfers as it is presented in section 3.3.

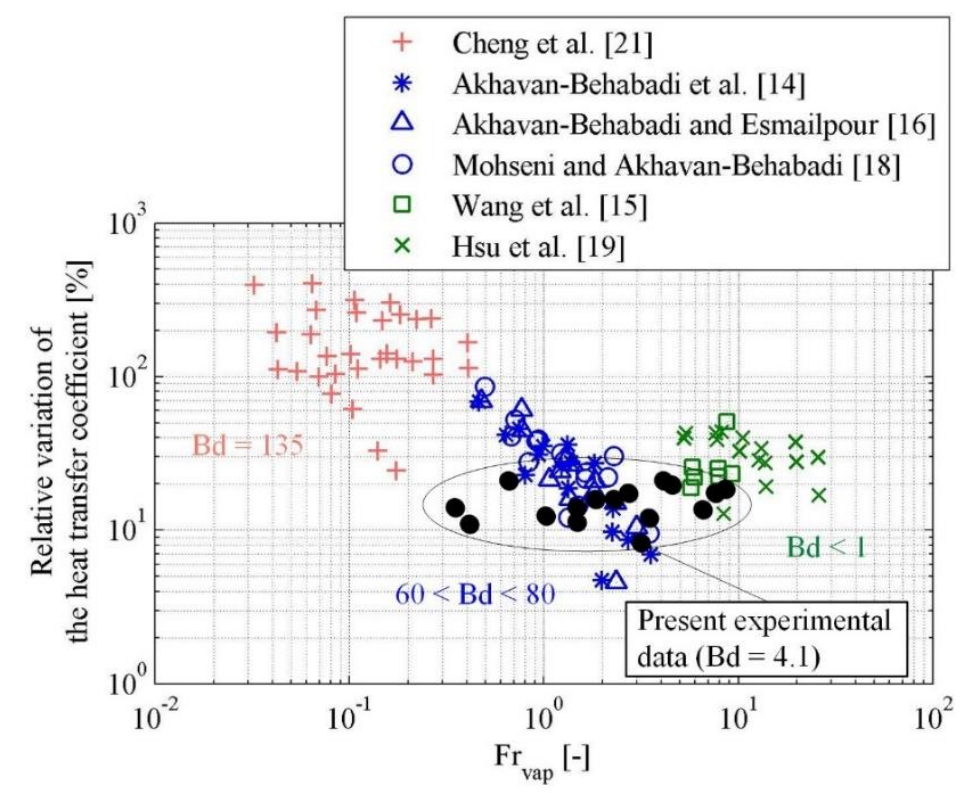

Figure 14: Relative variations of the heat transfer coefficient with the inclination observed in the literature as a function of the vapour Froude number 


\subsection{Comparison with asymptotic models}

The asymptotic models of the literature consider the variations of the respective intensities of the nucleate boiling and the convective boiling with the experimental conditions to predict the variation of the heat transfer coefficient. To calculate the nucleate boiling term, these models use correlations coming from the pool boiling literature. The convective term is calculated from usual correlations of prediction of the Nusselt number for single-phase flows. The respective weights of the nucleate boiling and the convective boiling are taken into consideration by using two coefficients, generally noted $S$ for the nucleate boiling and $E$ for the convective boiling. For an asymptotic model of order $n$, the expression of the flow boiling heat transfer coefficient is as follows:

$$
\alpha=\left[\left(S \alpha_{n u c}\right)^{n}+\left(E \alpha_{c o n v}\right)^{n}\right]^{\frac{1}{n}}
$$

with $\alpha_{n u c}$ the heat transfer coefficient for the nucleate boiling and $\alpha_{c o n v}$ the heat transfer coefficient for the convective boiling. $S$ is the extinction factor, which stands for the weight of the nucleate boiling while $E$ is the enhancement factor, which represents the weight of the convective boiling. Consequently, these models are not only able to predict the variations of the heat transfer coefficient with the experimental conditions but also the weights of the nucleate boiling and the convective boiling.

The accuracy of the predictions of eight asymptotic models of the literature was tested for the present dataset. All the details about the correlations, especially the calculation of the extinction factor $S$ and the enhancement factor $E$, are provided in [28]. For each model, the accuracy is analysed in terms of Mean Absolute Percentage Error (MAPE), Mean Percentage Error (MPE), Percentage of Experimental Data Captured within $\pm 50 \%$ (PEDC50), Percentage of Experimental Data Captured within $\pm 30 \%$ (PEDC30) and Percentage of Experimental Data Captured within $\pm 10 \%$ (PEDC10).The MAPE and MPE are calculated as follows:

$$
\begin{aligned}
\text { MAPE } & =\sum\left|\frac{\alpha_{\text {pred }}-\alpha_{\text {meas }}}{\alpha_{\text {meas }}}\right| \\
M P E & =\sum \frac{\alpha_{\text {pred }}-\alpha_{\text {meas }}}{\alpha_{\text {meas }}}
\end{aligned}
$$

The results in terms of statistical indicators are presented in Table 3.

Table 3: Heat transfer coefficient prediction accuracy of eight asymptotic models of the literature

\begin{tabular}{lccccc} 
& $\begin{array}{c}\text { MAPE } \\
{[\%]}\end{array}$ & $\begin{array}{c}\text { MPE } \\
{[\%]}\end{array}$ & $\begin{array}{c}\text { PEDC50 } \\
{[\%]}\end{array}$ & $\begin{array}{c}\text { PEDC30 } \\
{[\%]}\end{array}$ & $\begin{array}{c}\text { PEDC10 } \\
{[\%]}\end{array}$ \\
\hline Chen [29] & 57 & 57 & 40 & 10 & 0 \\
Gungor and Winterton [30] & 79 & 79 & 20 & 15 & 2 \\
Kandlikar [31] & 46 & -42 & 51 & 38 & 6 \\
Liu and Winterton [32] & 32 & 21 & 89 & 36 & 9 \\
Kandlikar and Balasubramanian [33] & 55 & -49 & 39 & 16 & 5 \\
Zhang et al. [34] & 52 & 49 & 66 & 34 & 11 \\
Saitoh et al. [35] & 34 & 32 & 82 & 34 & 13 \\
Bertsch et al. [36] & 16 & 9 & 100 & 94 & 29 \\
\hline
\end{tabular}


The model of Bertsch et al. [36] appears to be the best one to predict the variation of the heat transfer coefficient for the present dataset with all the best statistical indicators. The distribution of the predictions of the model of Bertsch et al. [36] for the present experimental database is presented in Figure 15. The particularly good agreement of this model with the experimental data can be explained by the similar experimental conditions of the underlying database of the model. Indeed, the correlation of Bertsch et al. [36] was developed from tests which were carried out with refrigerant flows in micro and mini-channels, corresponding to Bond numbers ranging from 0.06 to 11 . It is an asymptotic model based on equation (12) with :

$$
\begin{aligned}
& n=1 ; S=1-x ; F=1+80\left(x^{2}-x^{6}\right) e^{-0.6 / \sqrt{B d}} \\
& \alpha_{n u c}=55 P_{r}^{0.12}\left(-\log _{10} P_{r}\right)^{-0.55} M^{-0.5} \varphi^{0.67}, \\
& \alpha_{c o n v}=(1-x) \alpha_{l i q}+x \alpha_{v a p} \\
& \text { with } \alpha_{j}=\left[3,66+\frac{0,0668 \frac{d_{i}}{z} R e_{j} P r_{j}}{1+0,04 \frac{d_{i}}{z} R e_{j} P r_{j}^{\frac{2}{3}}}\right] \frac{\lambda_{j}}{d_{i}} \text { for } j=\text { vap and liq }
\end{aligned}
$$

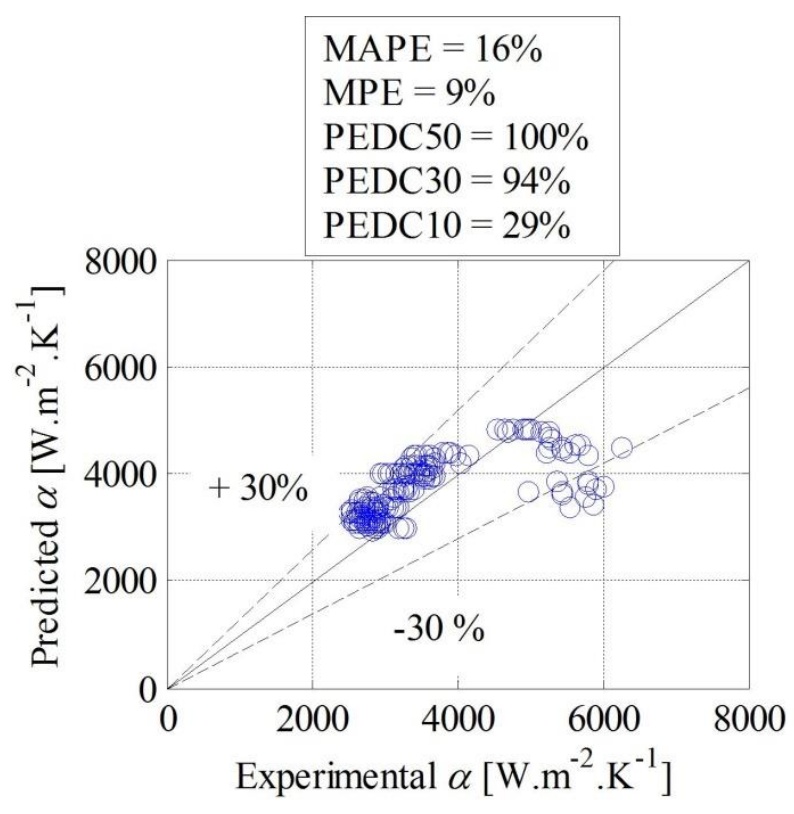

Figure 15: Predictions of the Bertsch et al. [36] model for the present experimental data

\subsection{Discussion about the effect of inclination on heat transfer}

The asymptotic models are able to predict not only the heat transfer coefficient behaviour but also the effect of the experimental conditions on the respective weights of the two heat transfer modes. As it is impossible to measure directly the importance of each mode, the asymptotic models can be used as a tool to better understand the experimental results. The model of Bertsch et al. [36] being the best asymptotic model to predict the heat transfer coefficient behaviour, it is likely the best to represent well the physics involved in the considered configuration. Its predictions in terms of nucleate boiling and convective boiling can thus be calculated and analysed for the conditions of the experiments. They are 
presented on Figure 16 in the case of the data obtained in horizontal configuration with a mass velocity of $150 \mathrm{~kg} \cdot \mathrm{m}^{-2} \cdot \mathrm{s}^{-1}$. The transition observed experimentally between annular and intermittent flow is represented by the vertical dashed red line. Representative frames of the flow are presented for vapour qualities of $0.13,0.3$ and 0.7 , which illustrates the transitions in terms of flow patterns and intensity of nucleation.

As it is observed in the transparent evaporator, the model of Bertsch et al. [36] predicts the decrease of the nucleate boiling with the vapour quality. Simultaneously, the convective boiling increases. These variations with the vapour quality result in a transition of dominant heat transfer modes for a vapour quality equal to 0.38 . the latter is indicated by means of the vertical dashed green line in Figure 16.

In the present study, the transition between the intermittent and the annular flow patterns was observed for a vapour quality of about 0.2 and slightly varied with the inclination. As a consequence, in the present study, it exists three kinds of couplings between the heat transfer modes and the flow patterns:

- In the case of a vapour quality lower than about 0.2 , the two-phase flow is intermittent and the dominant heat transfer mode is the nucleate boiling. Nucleate boiling mainly depends on the heat flux and the roughness of the inner wall. It is very slightly affected by the inclination and the effect of the inclination on the heat transfer coefficient is weak.

- For a vapour quality between about 0.2 and about 0.4 , the two-phase flow is annular and the dominant heat transfer is nucleate boiling. For the same reason as exposed previously, the inclination does not affect much the heat transfer.

- With a vapour quality higher than about 0.4 , the two-phase flow is annular and the dominant heat transfer mode is the convective boiling. The intensity of the convective boiling is directly conditioned by the variations of the thermal boundary layer with the experimental conditions. It may be impacted by the experimental conditions when the liquid film is sufficiently thin. In the present study, the liquid film may be thin in the case of high vapour qualities but in this case, the flow is annular and weakly depends on the orientation. Consequently, the inclination has a low effect on the heat transfer coefficient.

As a conclusion, it seems that the shift between the heat transfer modes and the flow pattern transitions is responsible of the lack of inclination effect on the heat transfer coefficients. An inversion of this shift would enhance the effect of inclination. Indeed, if the nucleate to convective boiling transition would occur at a lower vapour quality than the intermittent to annular flow pattern transition, the dominant heat transfer mode could be convective boiling while the flow would be intermittent. Consequently, both flow pattern and heat transfer mode would be impacted by the inclination, which would enhance the effect of the inclination on heat transfer. This behaviour may be reached for low reduced pressure conditions. 


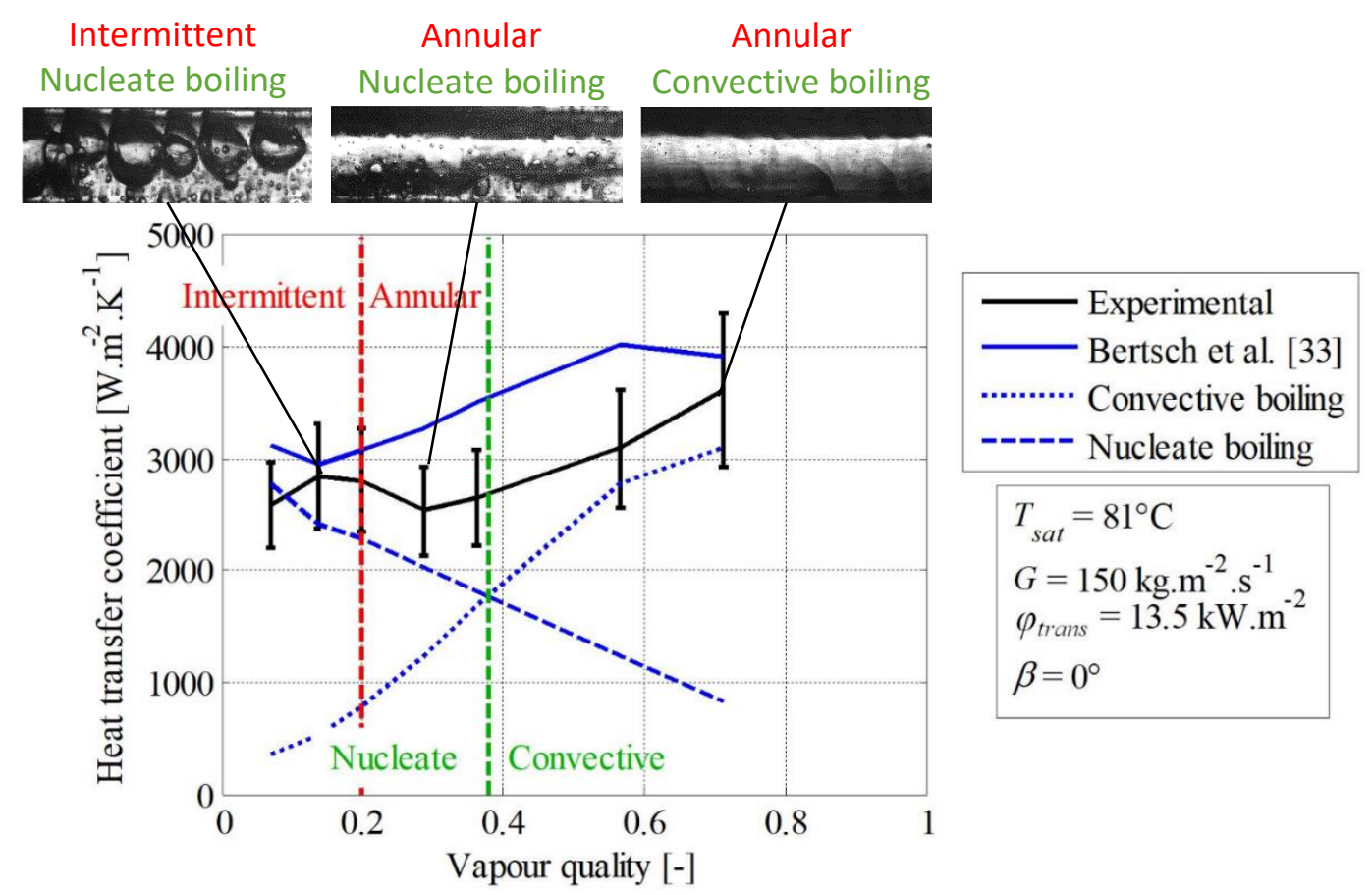

Figure 16: Prediction of the variations of the nucleate and convective heat transfer mode with vapour quality from Bertsch et al. [36] model for $T_{\text {sat }}=81^{\circ} \mathrm{C}$ and $G=150 \mathrm{~kg} \cdot \mathrm{m}^{-2} \cdot \mathrm{s}^{-1}$

\section{Conclusions}

Measurements of heat transfer coefficients were carried out in the case of R245fa flow boiling in an inclined mini-channel. The whole range of inclination was tested. The evaporator, composed of a $1.6 \mathrm{~mm}$ inner diameter sapphire tube coated with ITO was transparent. It enabled the visualisation of the flow directly in the evaporator and it was possible to observe the nucleation intensity.

The measurement of the outer wall evaporator temperature was ensured by means of an infrared camera and a post-processing. It enabled the acquisition of the temperature profile along the infrared visualisation section. The local heat transfer coefficient was then calculated for each abscissa with a local thermal model considering the heat losses by natural convection and radiation around the evaporator. The acquisition of the mean heat transfer coefficient along the infrared visualisation section was carried out for various experimental conditions in terms of vapour quality (from 0.03 to 0.85 ) and mass velocity (150 and $\left.300 \mathrm{~kg} \cdot \mathrm{m}^{-2} \cdot \mathrm{s}^{-1}\right)$.

The variations of the heat transfer coefficient with both vapour quality and mass velocity were first analysed in the case of a horizontal flow $\left(\beta=0^{\circ}\right)$. It was observed that the nucleate boiling and the convective boiling modes were in competition in the present study. This observation was confirmed with the visualisation of the flow in the evaporator. It was observed that the intensity of the nucleation decreased with the inertia of the vapour phase. 
The effect of the inclination on heat transfer was then tested and showed to be almost absent in the present study. This observation was interpreted with the intermittent to annular flow pattern transition and the nucleate to convective boiling heat transfer regime transition. The shift between these two transitions was predicted by the model of Bertsch et al. [36] which brought an interpretation to the low effect of the inclination on the R245fa flow boiling heat transfer in the present mini-channel.

\section{References}

[1] S. Lips, J.P. Meyer, Two-phase flow in inclined tubes with specific reference to condensation: A review, Int. J. Multiph. Flow. 37 (2011) 845-859. doi:10.1016/j.ijmultiphaseflow.2011.04.005.

[2] A.J. Ghajar, J. Kim, A non-boiling two-phase flow heat transfer correlation for different flow patterns and pipe inclination angles, in: Proc. 2005 ASME Summer Heat Transf. Conf., 2005: pp. 17-22.

[3] A.J. Ghajar, C.C. Tang, Heat Transfer Measurements, Flow Pattern Maps, and Flow Visualization for Non-Boiling Two-Phase Flow in Horizontal and Slightly Inclined Pipe, Heat Transf. Eng. 28 (2007) 525-540. doi:10.1080/01457630701193906.

[4] M.J. Vaze, J. Banerjee, Effect of inclination on flow and thermal characteristics of air-water two-phase flow: an experimental investigation, in: 2011: pp. 213-224. doi:10.2495/MPF110181.

[5] S.M. Bhagwat, A.J. Ghajar, Experimental investigation of non-boiling gas-liquid two phase flow in upward inclined pipes, Exp. Therm. Fluid Sci. 79 (2016) 301-318. doi:10.1016/j.expthermflusci.2016.08.004.

[6] S.M. Bhagwat, A.J. Ghajar, Experimental investigation of non-boiling gas-liquid two phase flow in downward inclined pipes, Exp. Therm. Fluid Sci. 89 (2017) 219-237. doi:10.1016/j.expthermflusci.2017.08.020.

[7] A. Cioncolini, J.R. Thome, Liquid film circumferential asymmetry prediction in horizontal annular two-phase flow, Int. J. Multiph. Flow. 51 (2013) 44-54. doi:10.1016/j.ijmultiphaseflow.2012.12.003.

[8] M.M. Shah, Applicability of Correlations for Boiling/Condensing in Macrochannels to Minichannels, Heat Mass Transf. Res. J. 2 (2018).

[9] S. Lips, J.P. Meyer, Experimental study of convective condensation in an inclined smooth tube. Part I: Inclination effect on flow pattern and heat transfer coefficient, Int. J. Heat Mass Transf. 55 (2012) 395-404. doi:10.1016/j.ijheatmasstransfer.2011.09.033.

[10] I. Marchuk, Y. Lyulin, O.A. Kabov, Theoretical and experimental study of convective condensation inside a circular tube, Interfacial Phenom. Heat Transf. 1 (2013).

[11] S.G. Mohseni, M.A. Akhavan-Behabadi, M. Saeedinia, Flow pattern visualization and heat transfer characteristics of R-134a during condensation inside a smooth tube with different tube inclinations, Int. J. Heat Mass Transf. 60 (2013) 598-602.

[12] J.P. Meyer, J. Dirker, A.O. Adelaja, Condensation heat transfer in smooth inclined tubes for R134a at different saturation temperatures, Int. J. Heat Mass Transf. 70 (2014) 515-525.

[13] F. Xing, J. Xu, J. Xie, H. Liu, Z. Wang, X. Ma, Froude number dominates condensation heat transfer of R245fa in tubes: Effect of inclination angles, Int. J. Multiph. Flow. 71 (2015) 98115. doi:10.1016/j.ijmultiphaseflow.2015.01.005.

[14] A.O. Adelaja, J. Dirker, J.P. Meyer, Convective condensation heat transfer of R134a in tubes at different inclination angles, Int. J. Green Energy. 13 (2016) 812-821. doi:10.1080/15435075.2016.1161633.

[15] M.A. Akhavan-Behabadi, S.G. Mohseni, S.M. Razavinasab, Evaporation heat transfer of R134a inside a microfin tube with different tube inclinations, Exp. Therm. Fluid Sci. 35 (2011) 996-1001. doi:10.1016/j.expthermflusci.2011.01.020. 
[16] C.-C. Wang, W.-J. Chang, C.-H. Dai, Y.-T. Lin, K.-S. Yang, Effect of inclination on the convective boiling performance of a microchannel heat sink using HFE-7100, Exp. Therm. Fluid Sci. 36 (2012) 143-148. doi:10.1016/j.expthermflusci.2011.09.006.

[17] M.A. Akhavan-Behabadi, M. Esmailpour, Experimental study of evaporation heat transfer of R-134a inside a corrugated tube with different tube inclinations, Int. Commun. Heat Mass Transf. 55 (2014) 8-14. doi:10.1016/j.icheatmasstransfer.2014.03.003.

[18] A. Kundu, R. Kumar, A. Gupta, Flow boiling heat transfer characteristics of R407C inside a smooth tube with different tube inclinations, Int. J. Refrig. 45 (2014) 1-12. doi:10.1016/j.ijrefrig.2014.06.009.

[19] S.G. Mohseni, M.A. Akhavan-Behabadi, Flow pattern visualization and heat transfer characteristics of R-134a during evaporation inside a smooth tube with different tube inclinations, Int. Commun. Heat Mass Transf. 59 (2014) 39-45. doi:10.1016/j.icheatmasstransfer.2014.10.018.

[20] L.-C. Hsu, S.-W. Cion, K.-W. Lin, C.-C. Wang, An experimental study of inclination on the boiling heat transfer characteristics of a micro-channel heat sink using HFE-7100, Int. Commun. Heat Mass Transf. 62 (2015) 13-17. doi:10.1016/j.icheatmasstransfer.2015.01.007.

[21] G. Bamorovat Abadi, C. Moon, K.C. Kim, Effect of gravity vector on flow boiling heat transfer, flow pattern map, and pressure drop of R245fa refrigerant in mini tubes, Int. J. Multiph. Flow. 83 (2016) 202-216. doi:10.1016/j.ijmultiphaseflow.2016.04.007.

[22] W.-L. Cheng, H. Chen, S. Yuan, Q. Zhong, Y.-F. Fan, Experimental study on heat transfer characteristics of R134a flow boiling in " $\Omega$ "-shaped grooved tube with different flow directions, Int. J. Heat Mass Transf. 108 (2017) 988-997. doi:10.1016/j.ijheatmasstransfer.2016.12.053.

[23] R. Charnay, R. Revellin, J. Bonjour, Flow boiling characteristics of R-245fa in a minichannel at medium saturation temperatures, Exp. Therm. Fluid Sci. 59 (2014) 184-194. doi:10.1016/j.expthermflusci.2014.01.011.

[24] T. Layssac, Contribution à l'étude phénoménologique de l'ébullition convective en mini-canal, Thèse de doctorat, INSA de Lyon, Université de Lyon, 2018.

[25] T.H. Kim, E. Kommer, S. Dessiatoun, J. Kim, Measurement of two-phase flow and heat transfer parameters using infrared thermometry, Int. J. Multiph. Flow. 40 (2012) 56-67. doi:10.1016/j.ijmultiphaseflow.2011.11.012.

[26] S.W. Churchill, H.H.S. Chu, Correlating equations for laminar and turbulent free convection from a horizontal cylinder, Int. J. Heat Mass Transf. 18 (1975) 1049-1053. doi:10.1016/00179310(75)90222-7.

[27] T. Layssac, S. Lips, R. Revellin, Experimental study of flow boiling in an inclined mini-channel: Effect of inclination on flow pattern transitions and pressure drops, Exp. Therm. Fluid Sci. 98 (2018) 621-633. doi:10.1016/j.expthermflusci.2018.07.004.

[28] R. Charnay, Experimental study of flow boiling in horizontal minichannels at high saturation temperature, Lyon, INSA, 2014. http://www.theses.fr/2014ISAL0047 (accessed October 21, 2016).

[29] J.C. Chen, A correlation for boiling heat transfer to saturated fluids in convective flow, ASME Publ. (1964).

[30] K.E. Gungor, R.H.S. Winterton, A general correlation for flow boiling in tubes and annuli, Int J Heat Mass Transf. 29 (1986) 351-358.

[31] S.G. Kandlikar, A General Correlation for Saturated Two-Phase Flow Boiling Heat Transfer Inside Horizontal and Vertical Tubes, J. Heat Transf. 112 (1990) 219-228. doi:10.1115/1.2910348.

[32] Z. Liu, R.H.S. Winterton, A general correlation for saturated and subcooled flow boiling in tubes and annuli, based on a nucleate pool boiling equation, Int J Heat Mass Transf. 34 (1991) 2759-2766.

[33] P. Kandlikar, S. Balasubramanian, Extending the applicability of the flow boiling correlation to low Reynolds number flows in microchannels, ASME - First Int. Conf. Microchannels Minichannels April 21-23 Rochester N. Y. USA. (2003) 603-608.

[34] W. Zhang, T. Hibiki, K. Mishima, Correlation for flow boiling heat transfer in mini-channels, Int. J. Heat Mass Transf. 47 (2004) 5749-5763. doi:10.1016/j.ijheatmasstransfer.2004.07.034. 
[35] S. Saitoh, H. Daiguji, E. Hihara, Correlation for boiling heat transfer of R-134a in horizontal tubes including effect of tube diameter, Int. J. Heat Mass Transf. 50 (2007) 5215-5225. doi:10.1016/j.ijheatmasstransfer.2007.06.019.

[36] S.S. Bertsch, E.A. Groll, S.V. Garimella, Effects of heat flux, mass flux, vapor quality, and saturation temperature on flow boiling heat transfer in microchannels, Int. J. Multiph. Flow. 35 (2009) $142-154$. 